\section{Abnormal Flowering in Pecan Associated with Freezing Temperature}

\author{
Darrell Sparks \\ Department of Horticulture, University of Georgia, Athens, GA 30602 \\ Additional index words. Carya illinoinensis, budbreak, heating degree days, bud \\ development, freeze injury, sex expression
}

Abstract. Freezing and damaging temperatures were imposed on 'Desirable' pecan [Carya illinoinensis (Wangenh) K. Koch] trees before budbreak and again during the beginning of pistillate anthesis. Freezing temperatures imposed before budbreak resulted in abnormal flowering; freezing temperatures during anthesis did not. Abnormal flowering depends on both a critical temperature (about -1.7 to $-2.2 \mathrm{C}$ ) and a critical stage of pistillate flower bud development within the 8- to 10-day interval before budb r e a k.

Normally, pecan is monoecious. Pistillate flowers are borne terminally on current-season shoots, and staminate flowers are borne at the base of those shoots and along the length of the supporting 1-year-old branch. However, both pistillate and staminate flower development has been observed at the shoot terminus (Cole and Hunter, 1965; Hagler, 1956; Woodroof and Woodroof, 1929), indicating that the flowering habit in pecan can be unstable under certain conditions.

Woodroof and Woodroof (1929) described two types of "perfect flower clusters," i.e., those with staminate and pistillate parts. One type had one or more staminate inflorescences borne at the terminus of the pistillate flower cluster, and the other type had staminate inflorescences at the base of the pistillate cluster. They attributed the formation of staminate flowers on the terminus of pistillate inflorescences of pecan to genetic instability. They observed this phenomenon during three successive years on a single 'Beveridge' tree. Because 30 other cultivars in the same orchard did not exhibit this abnormality, Woodroof and Woodroof assumed genetic instability in sex expression for this cultivar. They proposed that the second type of perfect flowers (staminate flower development at the base of the pistillate inflorescences), which occurred on a single 'Jerome' tree, was due to excessive stimulation of lateral buds. Later, Hagler (1956) observed abnormal flowering in Alabama following damage from the late spring freeze of 1955. Cole and Hunter (1965), working in Georgia, also observed abnormal flowering on seedlings and eight cultivars following the same late spring freeze. Their photographs showed that, in addition to the perfect flower cluster described by Woodroof and Woodroof, the cluster may consist of a single staminate or three staminate

Received for publication 28 Oct. 1991. Accepted for publication 4 Mar. 1992. Appreciation is expressed to Donnie Maxey for photography and to Gloria Belvan for technical assistance. The cost of publishing this paper was defrayed in part by the payment of page charges. Under postal regulations, this paper therefore must be hereby marked advertisement solely to indicate this fact. inflorescences, both without pistillate flowers. In addition, the perfect flower cluster may have a single staminate inflorescence in the terminus as well as a single staminate inflorescence at the base. Cole and Hunter (1965) suggested that atypical flowering reflects abnormal physiology of lateral buds resulting from unseasonable low temperature, rather than genetic instability. Personal observations indicate 'Desirable' is espe- cially sensitive to environmental conditions that cause abnormal flowering, as judged by the frequency with which this cultivar exhibits the phenomenon. In the current study, I examined the hypothesis that unseasonally low temperatures near the time of budbreak cause abnormal flowering.

The data for abnormal flowering were collected from a study originally designed to evaluate the effect of spring temperature on budbreak, pollen shedding, stigma receptivity, and subsequent fruit development of 16year-old 'Desirable' trees growing on the Univ. of Georgia Horticulture Farm, Watkinsville. Differences in temperature were obtained by constructing $4.3 \times 4.3 \times 4.3$ $\mathrm{m}$ unheated plastic $(0.1 \mathrm{~mm})$ greenhouses over individual trees. Treatments examined were trees enclosed in a greenhouse for 1) $\approx 3$ weeks before budbreak (17 Mar.-7 Apr.); 2) 4 weeks following budbreak (8 Apr.-6 May); 3) $\approx 7$ weeks, beginning $\approx 3$ weeks before budbreak to 4 weeks after budbreak, and 4) trees not enclosed. Ambient temperature was recorded per tree as maximum and minimum per 24 -h period within the tree structure at a height of $\approx 1.8 \mathrm{~m}$ and $\approx 0.5 \mathrm{~m}$ from the tree's center. Heating degree days (number of degrees the mean daily temperature is above a given base) were calculated

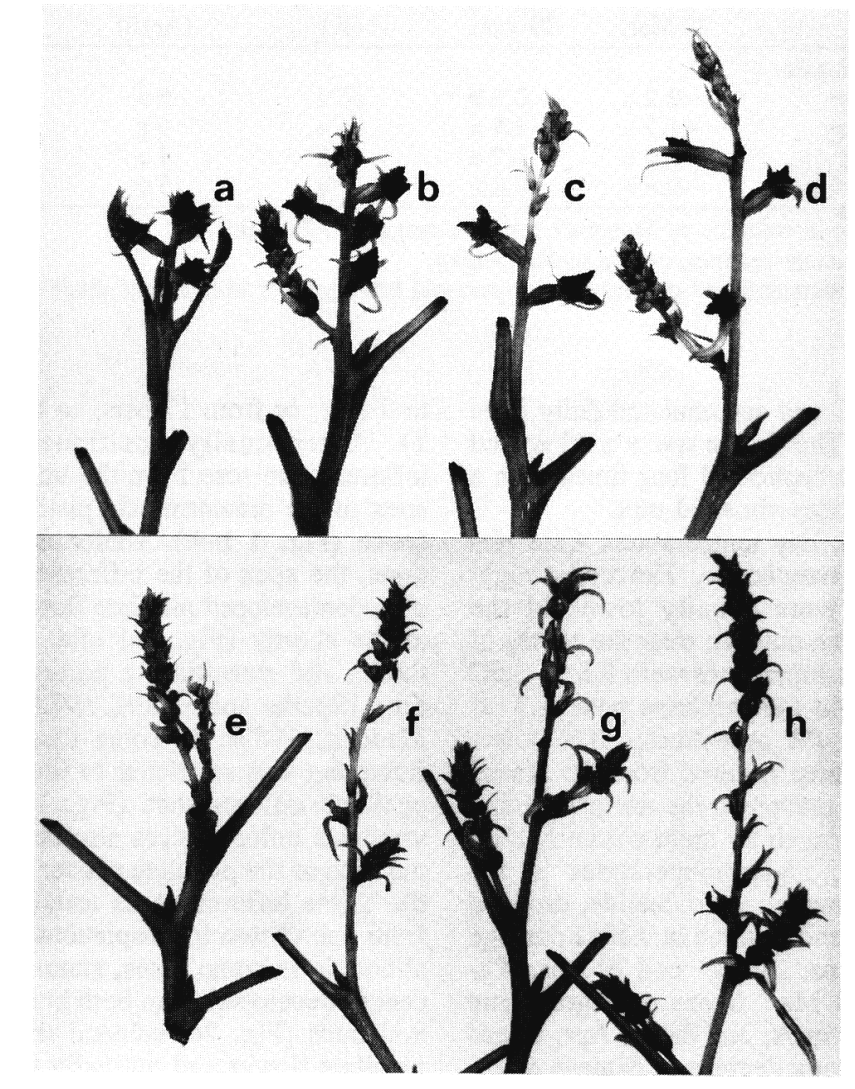

Fig. 1. Abnormal flowering in 'Desirable' pecan following freeze damage. Normal pistillate inflorescence (a); variations in abnormal flowering (b-h). In b, c, and d, a staminate inflorescence developed from the apex of the pistillate inflorescence. In $b$ and $d$, a staminate inflorescence also developed from a lateral bud subtending the basal-most pistillate flower. In e-h, pistillate inflorescences have been totally replaced by staminate inflorescences and a staminate inflorescence developed from a lateral bud subtending the basal-most pistillate flower. In $g$ and $h$, the lateral bud of the first leaf subtending the cluster also produced a staminate inflorescence. 


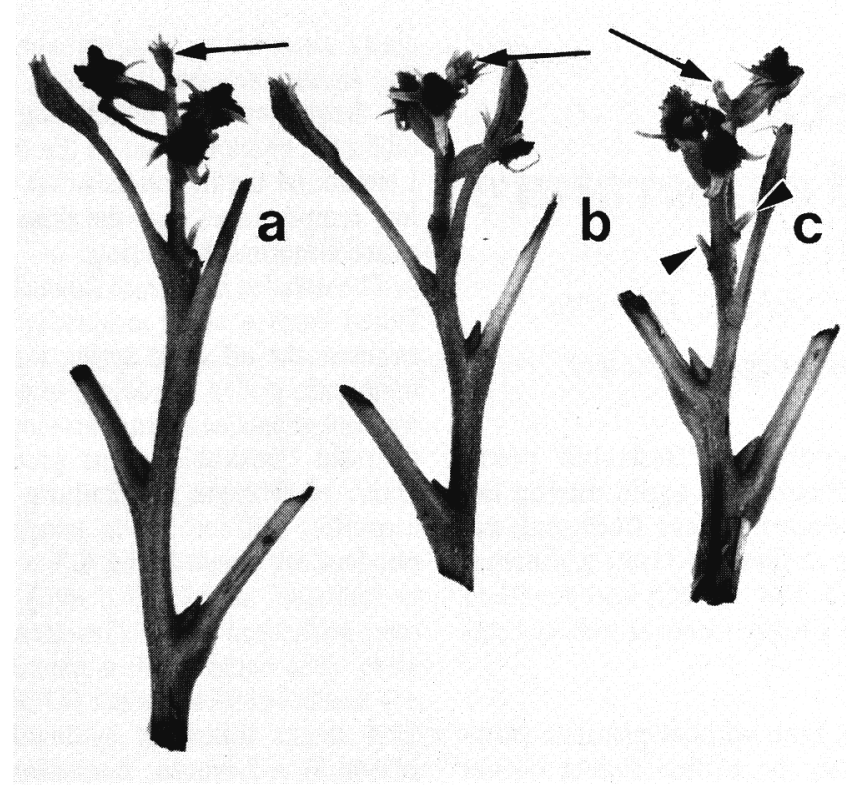

Fig. 2. Pistillate inflorescences of 'Desirable' pecan. Normal inflorescence (a) with apex (arrow) consisting of undeveloped pistillate flowers. This apex normally aborts (c). Abnormal inflorescence (b) in which the apex (arrow) is in the early stage of producing a staminate inflorescence. Normal inflorescence (c) in which the apex has aborted. The undersized pistillate flower (arrow) will also abort. Two lateral buds (triangles) subtending the basal-most pistillate flower.

Table 1. Association of abnormal flowering of 'Desirable' pecan with temperature. ${ }^{2}$

\begin{tabular}{|c|c|c|c|c|c|}
\hline \multirow[b]{2}{*}{ Treatment } & \multicolumn{2}{|c|}{ Min temp $\left({ }^{\circ} \mathrm{C}\right)$} & \multirow{2}{*}{$\begin{array}{c}\text { Abnormal } \\
\text { floweringy } \\
(\%)\end{array}$} & \multirow{2}{*}{$\begin{array}{c}\text { Budbreak } \\
\text { (April) }\end{array}$} & \multirow{2}{*}{$\begin{array}{c}\text { Heating } \\
\text { degree daysw } \\
\text { (17-27 Mar.) }\end{array}$} \\
\hline & 28 Mar. & 20 Apr. & & & \\
\hline $\begin{array}{l}\text { Greenhouse enclosure } \\
17 \text { Mar.-7 Apr. } \\
17 \text { Mar.-6 May } \\
8 \text { Apr.-6 May } \\
\text { Control } \\
\end{array}$ & $\begin{array}{r}-2.2 \mathrm{a} \\
-1.7 \mathrm{a} \\
0.0 \mathrm{~b} \\
-0.6 \mathrm{~b} \\
\end{array}$ & $\begin{array}{r}-0.6 \mathrm{~b} \\
-1.7 \mathrm{a} \\
-1.7 \mathrm{a} \\
0.0 \mathrm{~b} \\
\end{array}$ & $\begin{array}{r}56 \mathrm{a} \\
64 \mathrm{a} \\
0 \mathrm{~b} \\
0 \mathrm{~b} \\
\end{array}$ & $\begin{array}{l}5 \mathrm{a} \\
6 \mathrm{a} \\
4 \mathrm{a} \\
5 \mathrm{a} \\
\end{array}$ & $\begin{array}{l}52 \mathrm{a} \\
51 \mathrm{a} \\
24 \mathrm{~b} \\
22 \mathrm{~b}\end{array}$ \\
\hline
\end{tabular}

${ }^{2}$ Mean separation in columns by Duncan's multiple range test, $P \leq 0.01$.

'Based on 25 clusters per tree, counts made 13 May.

Fifty percent budbreak based on thirty-two 1-year-old branches per tree; counts made daily. "Base 7.2C.

from base $7.2 \mathrm{C}$ and accumulated daily from 17 to 28 Mar. The design was a randomized complete block replicated four times with a single tree per experimental unit.

As expected, day temperatures were elevated in the greenhouse. However, night temperatures were usually lower in the greenhouses than outside; over the course of the study, day temperatures were $9.8 \pm 3.5 \mathrm{C}$ higher and night temperatures were $1.3 \pm$ 1.0C lower in the greenhouse. The lower night temperatures resulted from the closed system, which prevented the normal mixing of cold and warm air by night currents. During the study, night temperatures in the greenhouses, in contrast to outside, dropped below $-1.0 \mathrm{C}$ and resulted in visible damage on two occasions, 28 Mar. and 20 Apr. (Table 1). The 28 Mar. freeze damaged some of the swelling buds, and the 20 Apr. freeze resulted in varying degrees of damage to expanding leaves and to catkins and pistillate inflorescences. Damage was evident by browning and death of a portion of the exposed tissues.

Following pistillate anthesis, a wide range of abnormal flowers (Fig. 1) developed on trees enclosed in greenhouses from 17 Mar. to 7 Apr. or from 17 Mar. to 6 May (Table 1). A terminally positioned staminate inflorescence rose from the underdeveloped apex of the indeterminate pistillate inflorescence (Fig. 1 b-h). Under normal conditions, the apex of the inflorescence consists of underdeveloped pistillate flowers (Fig. 2a), aborts shortly (Fig. 2c) after pistillate anthesis, and constitutes a portion of the first drop (Sparks and Heath, 1972; Sparks and Madden, 1985). In some cases, abnormal flowering was restricted to the apex of the pistillate inflorescence (Fig. 1c), but often staminate inflorescences also developed from the base of the pistillate cluster (Fig. $1 \mathrm{~b}$ and d). These inflorescences usually developed from one of two inconspicuous lateral buds; although, in some cases, staminate inflorescences developed from both buds. These lateral buds (Fig. 2c) subtend the basal-most pistillate flower and normally do not break; instead, they usually abscise shortly after pistillate anthesis. Sometimes the cluster consisted only of staminate flowers (Fig. 1 e-h). In these cases, inflorescences always developed from the apex and, in addition, from lateral buds (Fig. 1 e and f) or both lateral buds and the bud in the leaf subtend-

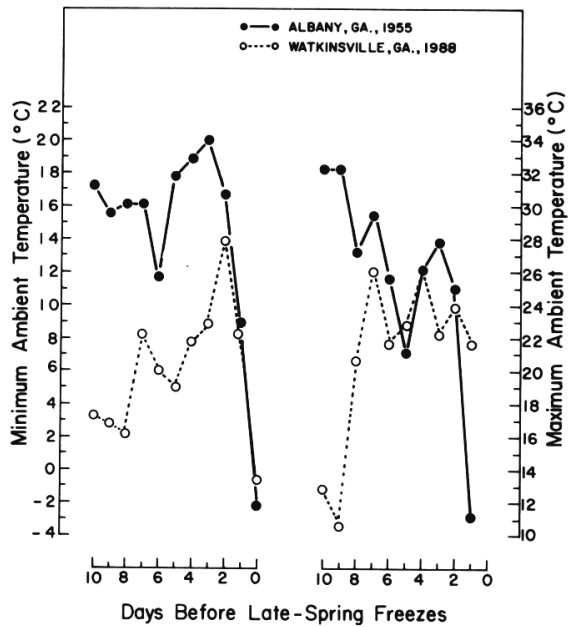

Fig. 3. Minimum and maximum ambient temperatures preceding two late-spring freezes. Pecan trees were damaged by the freezes and subsequently produced abnormal flowers. (Note the two scales do not cover the same temperature range, but the scales are identical.)

ing the cluster (Fig. $1 \mathrm{~g}$ and $\mathrm{h}$ ). The atypical staminate flowers produced and dehisced pollen.

Counts of abnormal flowering were made to examine the relationship to treatment and the two freezes. Abnormal flowers were produced only on trees that were enclosed in a greenhouse from 17 Mar. to $7 \mathrm{Apr}$. or from 17 Mar. to 6 May (Table 1). Trees enclosed from 8 Apr. to 6 May and exposed to the 20 Apr. freeze did not produce abnormal flowers even though they were exposed to the same minimum temperature of $-1.7 \mathrm{C}$ on 20 Apr. as trees enclosed during the 28 Mar. freeze. Furthermore, trees exposed to damaging temperature on both 28 Mar. and 20 Apr. (the 17 Mar. to 6 May treatment) did not produce any more abnormal flowers than those exposed to damaging temperature only once, during 17 Mar. to $7 \mathrm{Apr}$.

These data (Table 1) indicate that induction of abnormal flowering depends on both a critical low temperature and a critical stage of pistillate flower bud development. The critical temperature is at least -1.7 to $-2.2 \mathrm{C}$. This critical range is proposed from the minimum temperatures of 28 Mar. and the association of abnormal flowering with these minimum temperatures. Assuming that abnormal flowering was induced from the 28 Mar. freeze and based on $50 \%$ budbreak occurring from 4 to 6 Apr., the critical stage for abnormal flower induction includes at least the 8 - to 10 -day interval before $50 \%$ budbreak.

At the time of the 28 Mar. freeze, budbreak (inner bud scale broken) had not occurred on any of the trees, but initial budbreak was near and began 3 days later on 31 Mar. Consequently, morphological differentiation of the pistillate inflorescence had either not begun or the inflorescence apex was just beginning to broaden (Wetzstein and Sparks, 1983) at the time of the freeze. By the 20 Apr. freeze, the pistillate inflorescence was visible on the apex of the shoot. Thus, any 
environmental influence, such as low temperature, that alters normal flower development would have a better chance of altering sex expression if imposed near the time of budbreak and before major morphological development (28 Mar. freeze) than if imposed after the pistillate inflorescence was visible (20 Apr. freeze). In this regard, abnormal flowering following the late spring freeze of 1955 (Cole and Hunter, 1965; Hagler, 1956) occurred on shoots that developed from secondary buds that broke after the freeze. These buds were likewise exposed to low temperature before major morphological development of the pistillate flowers.

Heat accumulation at the time of the 28 Mar. freeze was greater for trees that produced abnormal flowers than those that did not (Table 1). Thus, the possibility exists that flower bud development was more advanced from the higher heat accumulation (Matta et al., 1976) and that the nonenclosed trees would have also produced abnormal flowers if heat accumulation and flower development had been equal to enclosed trees. Or, an interaction may exist between temperature and stage of flower bud development. If so, the critical temperature range for induction of abnormal flowering may be higher and wider than the proposed -1.7 to $-2.2 \mathrm{C}$. Alternately, if there is no interaction and if bud development was more advanced on trees that were enclosed, the critical stage for abnormal flower induction may be less than the proposed 8- to 10-day interval preceding budbreak.

The possibility also exists that preconditioning temperatures might affect the critical temperature that causes abnormal flowering. Ambient maximum and minimum temperatures within the 10-day interval preceding the freeze were compared (Fig. 3) with those of the late Mar. 1955 freeze (Cole and Hunter, 1965), which was also followed by abnormal flowering. In 1955, freezes occurred on 23, 27, and 29 Mar. The 23 Mar. freeze was used as the reference date because this was the first freeze and because the minimum temperature $(-2.2 \mathrm{C})$ was the same as in the present study. Maximum temperatures were high and nearly consistent during the 6 to 7 days preceding the freezes. Also, in the case of both freezes, minimum temperatures dropped abruptly from relative high to freezing temperatures. Further study is required to determine if these patterns preconditioned the tree to flower abnormally.

\section{Literature Cited}

Cole, J.R. and J.H. Hunter. 1965. Abnormal flowering of pecans following freeze damage in 1965. Plant Dis. Rpt. 49:146-147.

Hagler, T.H. 1956. Freeze injury to pecans in Alabama. Proc. Southeastern Pecan Growers Assn. 49:9.

Matta, F.B., D.Y. Sullivan, and F.B. Widmoyer. 1976. The relationship between pistillate flower development and air temperature in 'Western' pecan. HortScience 11:492-493.

Sparks, D. and J.L. Heath. 1972. Pistillate flower and fruit drop of pecan as a function of time and shoot length. HortScience 7:402-404.
Sparks, D. and G.D. Madden. 1985. Pistillate flower and fruit abortion in pecan as a function of cultivar, time, and pollination. J. Amer. Soc. Hort. Sci. 110:219-223.

Wetzstein, H.Y. and D. Sparks. 1983. The mor- phology of pistillate flower differentiation in pecan. J. Amer. Soc. Hort. Sci. 108:997-1003.

Woodroof, J.G. and N.C. Woodroof. 1929. Abnormalities in pecan flowers. J. Hered. 21:3944. 